\title{
Predicting Product Uptake Using Bass, Gompertz, and Logistic Diffusion Models: Application to a Broadband Product
}

\author{
Franklin M. Lartey ${ }^{1}$ \\ ${ }^{1}$ Cox Communications, 6305 Peachtree Dunwoody Road, Atlanta, GA 30328, USA \\ Correspondence: Franklin M. Lartey, Cox Communications, 6305 Peachtree Dunwoody Road, Atlanta, GA 30328, \\ USA
}

Received: October 22, 2020

Accepted: October 30, 2020 Online Published: October 31, 2020

doi:10.5430/jbar.v9n2p5

URL: https://doi.org/10.5430/jbar.v9n2p5

\begin{abstract}
In today's competitive environment, broadband companies innovate to stay competitive, retain existing customers, and attract new customers. A recent innovative product in this industry is the deployment of the gigabit Internet service over fiber optic networks as a solution to the growing bandwidth demands from consumers. One determinant of the decision to deploy such product is the expectation of a positive return on investment (ROI) determined among others by the penetration or take rate of the product or service. Like any product, the adoption of the gigabit Internet is influenced by the reaction of customers to this innovation. Some customers are early adopters of the product while others might not be interested in higher bandwidth Internet connections or will simply adopt the product at a later time. The purpose of this paper was to identify a model that best predicts future trends in the uptake of the gigabit Internet product over fiber-to-the home (FTTH). To that effect, this study implemented three different models: Bass, Gompertz, and logistic diffusion models; analyzed their predictive abilities; and determined the best fit model in a FTTH brownfield scenario. The data used for the study were split into two sets: the first or training set was used to create the models and the second was used to validate their predicting abilities. The data analysis used the ordinary least squares (OLS) method to select the best fit model. The results suggested that while Gompertz best fitted the training data, Bass had a better forecasting power. In other words, the Bass diffusion model was best at forecasting future uptake of the gigabit Internet service, while Logistic optimistically forecasted above the take rate and Gompertz pessimistically forecasted below. These findings present various implications for researchers and practicians. For example, future research could replicate the study for different industries and products, while practicians could anticipate realistic financial results from the implementation of the findings.
\end{abstract}

Keywords: Gompertz model, Bass model, logistic model, diffusion model, Gompertz, Bass, diffusion, model, forecasting, predicting, FTTH, broadband, innovation

\section{Introduction}

With the fierce competition in the broadband industry, firms innovate to stay competitive, retain existing customers, and attract new customers (Lartey, 2015). One recent innovative product in this industry is the residential gigabit Internet connection over fiber to the home (FTTH) deployments. This product is offered in the United States by various Internet Service Providers (ISP) such as AT\&T, Centurylink, Comcast, Cox Communications, EPB, and Google, among others. Briglauer and Gugler (2019) posit in their study that a percentage increase in the adoption of end-to-end fiber-based broadband products could result in an increase of .002 to .005 percent in the gross domestic product (GDP). Service providers and researchers agree that gigabit over FTTH is a solution to the growing bandwidth demands from consumers and contemporary applications, and providers base their decision to deploy gigabit Internet over FTTH on the expectation of a positive return on investment (ROI).

The ROI on a gigabit FTTH deployment is determined among others by the monthly cost of the product to consumers and the penetration or take rate of the product. The adoption of the gigabit Internet service is influenced by the reaction of customers to this innovation, some customers being early adopters of the product while others might not be interested in higher bandwidth Internet connections, or will simply adopt the product at a later time as explained by Stragier et al. (2012). As such, organizations need efficient ways to forecast the penetration rate of innovative products to determine their viability and create strategies to improve their promotion and increase their take rates. In other words, organizations need to establish market potential early in the diffusion process as explained 
by Meade and Islam (2006). Unfortunately, many studies present conflicting suggestions regarding the models that best predict diffusion of various products in different industries.

In her study of diffusion models, Young (1993) collected time series data related to technological growth. After applying nine different diffusion models, she concluded that that Bass outperformed all other models when the maximum penetration was not known. In a similar study analyzing seventheen diffusion models in forecasting telecommunication markets, Meade and Islam (1995) found that both Gompertz and Logistic outperformed other complex methods. Michalakelis, Varoutas, and Sphicopoulos (2008) identified Gompertz to be a better fit compared to Bass and Logistic in their study of the diffusion of mobile telephony, while Bakher Naseri and Elliott (2013) found Bass to outperform Gompertz and Logistic in a study of online sales. In another study, Sudtasan and Mitomo (2017) compared Logistic, Gompertz, and Bass models in forecasting the growth of broadband markets in Thailand, including mobile telecommunications and fixed-broadband subscriptions. They concluded that the Gompertz diffusion model was the best of the three diffusion models in forecasting the growth of broadband markets in Thailand. With all these conflicting findings, it is hazardeous to apply recommendations related to a specific product in an industry onto another product in the same or a different industry without substantiation from prior studies. This explains the need for such study related to an innovative product like the gigabit Internet in the broadband industry.

The purpose of this paper is to identify a model that predicts future trends in the uptake of the FTTH gigabit Internet product. To that effect, this work will implement different diffusion models, study their predictive abilities, and determine the best fit based on data collected in a brownfield (fiber overlay) FTTH deployment. To achieve the stated goal, this paper assumes that the reader has a basic knowledge of the gigabit product and will thus present a literature of some diffusion models, apply diffusion models to collected data, and finally identify the model that best forecasts the product take rate.

\section{Diffusion of Innovation Theory}

Once a new product or service is created, it needs to be diffused or sold to customers and consumers who adopt it. To that effect, the diffusion of innovation theory seeks to explain how new or innovative products or services are adopted by the population (Rogers, 1979; Robinson, 2009). Diffusion is the process of communicating an innovation to individuals or organizations over a period of time. An innovation is a product, process, idea, or service perceived by individuals as something new. In diffusing innovation, units of adoption such as individuals or organizations share information leading to the spread of the innovation.

The diffusion of innovation theory offers different insights in the social change process by studying the factors that contribute in the spread of innovation, the importance of peer networks and word of mouth, and the importance of customer segments. This theory classifies consumers in five different segments or adopter categories based on their propensity to adopt an innovation. These five segments include innovators, early adopters, early majority, late majority, and laggards (Campbell, 2015; Robinson, 2009; Robert, 1979; Rogers, 1983).

\subsection{Inovators}

Innovators are first in adopting a new product or service. They are willing to deal with the initial imperfections and uncertainties of the innovation. Rogers (2003) posits that innovators are the gatekeepers of the innovation and they bring it outside the system for others such as early adopters to adopt the innovation.

\subsection{Early adopters}

Early adopters are in the lookout for opportunities. They are naturally inclined on setting trends and are instrumental in jumpstarting the success of an innovation. As explained by Robinson (2009), early adopters tend to be socially respected, well informed, and economically successful as opposed to innovators who seem idealistic, energetic, and fixated on the innovation. Like innovators, early adopters do not require too much persuasion to adopt the innovation.

\subsection{Early majority}

Individuals in the early majority segment act only after seeing the benefits of the innovation. They seek innovations that are proven, less disruptive, easy to use or implement, and provide positive experience and return (Robinson, 2009). Individuals in the early majority segment are deliberate in adopting an innovation as they take the time to analyze what is in it for them. Early majority generally represents $34 \%$ of all the adopters while innovators make $2.5 \%$ and early adopters $13.5 \%$. Overall, these three segments make $50 \%$ of all adopters of an innovation and are further classified by Rogers (2003) as early adopters of innovators, as opposed to imitators. 


\subsection{Late majority}

Like early majority, late majority represents one third (34\%) of the innovation adopters. Individuals in this segment tend to be uncomfortable with new ideas and adopt an innovation only after most of their peers have adopted it (Sahin, 2006). Peer pressure is always an efficient way of convincing the late majority to adopt an innovation. These individuals feel comfortable when there is less uncertainty regarding the innovation. They are not risk takers, but do not also want to be left behind.

\subsection{Laggars}

Laggards tend to focus on the high risks associated with an innovation, thus increasing their resistance in adopting it. As explained by Rogers (2003), their social network generally consists of individuals who are similar to them and they tend not to be in leadership roles. Indeed, being in a leadership role suggests having various communication channels and the necessary information to make an informed decision and take some levels of risk. Laggards represent the remaining $16 \%$ of adopters and for them, it is better late than never. Laggards and late majority represent $50 \%$ of the innovation adopters and Rogers (2003) classifies them under the group of late adopters or imitators as opposed to early adopters also called innovators.

\section{Diffusion models}

Diffusion models help in forecasting the uptake rate of new products and services, population growth, or even the potential spread of diseases. Many diffusion models have been used in the telecommunication and broadband industry, some of which include the Gompertz model, the Bass model, the Fisher-Pry model, the Logistic model, and the Box-Cox model, just to name a few. For example, Turk and Trkman (2011) used the Bass model to estimate the diffusion of broadband technology in European countries. Similarly, Radojicic, Markovic, Jankovic, and Draskovic (2012) used the Bass model to derive a new model to forecast traffic on a broadband transport network. Michalakelis et al. (2008) implemented the Bass, Gompertz, Fisher-Pry, Box-Cox, and Logistic models in their analysis of the diffusion of mobile telephony in Greece. The current study will use the Gompertz, Bass, and Logistic diffusion models in forecasting the penetration rate of the gigabit Internet in a FTTH brownfield deployment.

\subsection{General model}

Diffusion models are deterministic time functions with S-shaped curves also known as sigmoid patterns (Michalakelis, Varoutas, \& Sphicopoulos, 2008). There are two main categories of diffusion models, non-dynamic and dynamic models. Non dynamic models have a constant saturation level while the saturation levels of dynamic models change over time (Konstantinos \& Vasilios, 2011). In the case of the brownfield FTTH gigabit product, the saturation level changes over time because new builds increase the total number of households passed and number of potential customers. In general, the diffusion rate at time $t$ is represented by the differential equation:

$$
\frac{d Y(t)}{d t}=f(t) \times[S(t)-Y(t)]
$$

In this equation, $S(t)$ is the saturation or maximum adoption level expected at the time $t$. In the case of FTTH, it represents the total number of households passed at time $t$.

$Y(t)$ is the total penetration or uptake rate of the product or service at time $t$.

$f(t)$ is the diffusion coefficient representing the speed of diffusion.

The equation $[S(t)-Y(t)]$ represents the total potential adopters at the time $t$ and can be read: Total possible adopters minus total adopters, which gives the total potential adopters.

The diffusion equation can be represented on a graph where the $\mathrm{x}$ axis represents the time $t$ and the $\mathrm{y}$ axis the penetration rate. An example of such graph is shown on Figure 1. In an ideal situation, the graph forms a bell-shaped curve with the 5 segments of adopters represented. 


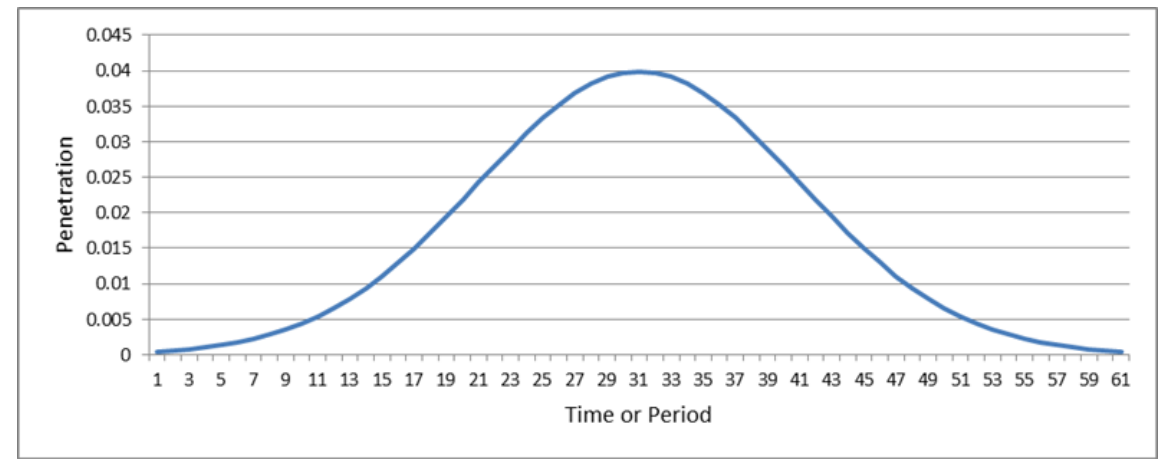

Figure 1. Normal curve of an uptake rate based on time

The tip of the curve represents the maximum penetration rate at any given time, and the corresponding time $t$ when this penetration occurs is the inflection point. After the inflection point, the rate of new adoptions declines until the end of the life cycle when it is replaced by a substitution product or a new innovation.

A transformation of this graph provides the graph on Figure 2 in which the $x$-axis still represents the time, but the $\mathrm{y}$-axis now represents the cumulative penetration over time as opposed to the penetration rate at a given time $t$ in the previous graph on Figure 1.

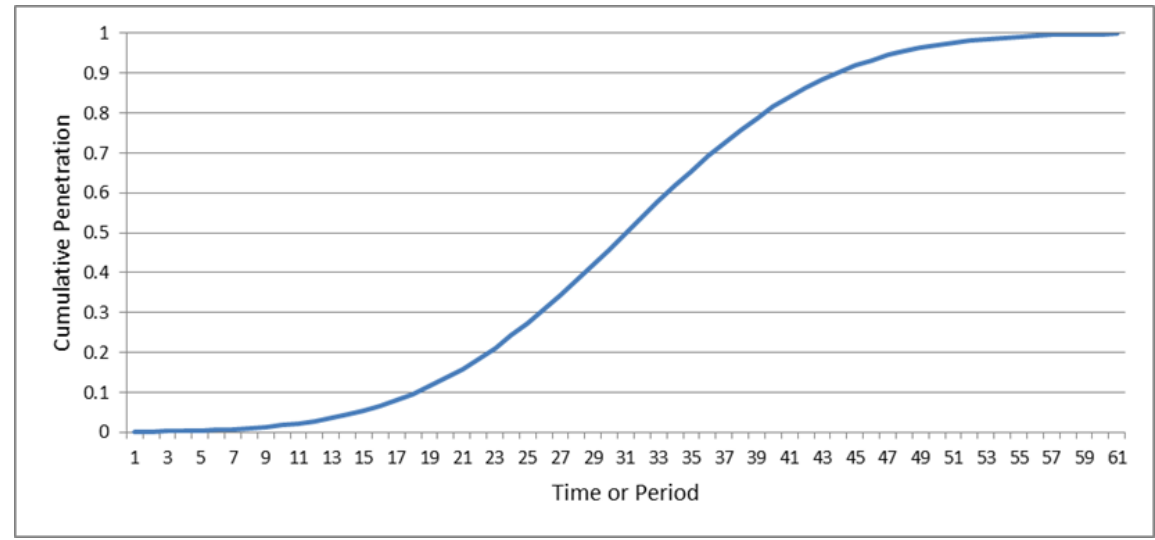

Figure 2. S-shaped curve of the cumulative penetration rate

This transformed graph produces an S-shaped curve also known as a sigmoid-like curve and all diffusion models discussed in this study follow this representation.

\subsection{Gompertz diffusion model}

The Gompertz model was created by Benjamin Gompertz in 1825 based on his law of human mortality which assumes that resistance to death reduces as age increases (Skiadas \& Skiadas, 2010). This model has since been adapted to various fields including innovation of technology where growth is slower at the beginning and at the end of the adoption period. As explained by Stragier, Seys, Evens, Evenepoel, Ooteghem, and Casier (2010), the Gompertz model is represented by the following equation:

$$
S(t)=m \cdot e^{-e^{-b(t-a)}}
$$

This representation of the Gompertz model was used by Berger (1981) in a study comparing the Gompertz model and logistic equation in analyzing the progression of plant disease. The model was also used by Michalakelis et al. (2008) in their study of the diffusion of mobile telephony in Greece, and by Diaz Perez et al. (2020) to compare various methods to forecast the growth of the COVID-19 pandemic. In another recent study of the propagation of the 
COVID-19 (SARS-Cov-2) virus, Levitt, Scaiewicz, and Zonta (2020) demonstrated that the cases grew in accordance with the Gompertz diffusion function. This allowed the research community to develop better algorithms to consistently fit the data and properly project cases. In equation (2), $a$ is the inflexion point indicating the point in time at which the growth of the innovation adoption reaches its peak and starts decreasing; $b$ is the growth rate or pace of adoption of the innovation; and $m$ is the market potential or the maximum number of possible adopters.

\subsection{Bass diffusion model}

The Bass diffusion model has its theoretical foundation in Roger's diffusion theory and was created by Frank M. Bass (1926-2006), professor of marketing science at the School of Management of the University of Texas in Dallas. Unlike the Gompertz model, the Bass model was specifically developed for the adoption of new products, with the assumption that "the probability of purchase at any time is related linearly to the number of previous buyers" (Bass, 1969, p. 226). This assumption is explained by Turk and Trkman (2011) who stated that "the conditional likelihood of adoption of a randomly chosen consumer at time $t$, given that the adoption has not yet occurred, is a linear function of the number of previous adopters" (p. 6). This suggests that the adoption rate of an innovation at any given time is influenced by previous adoptions communicated through channels such as marketing efforts and word-of-mouth promotions. The Bass model is represented using the following mathematical equation:

$$
F(t)=\frac{1-e^{-(p+q) \cdot t}}{1+\left(\frac{q}{p}\right) e^{-(p+q) \cdot t}}
$$

In this equation, $p$ and $q$ are probability estimates respectively representing the probability that a consumer will adopt the innovation (coefficient of innovation) and the probability of adoption by an imitator (coefficient of imitation). As such, these are positive real numbers and higher values of $p$ indicate an increased adoption rate in the earlier years, while higher values of $q$ indicate an increased adoption rate in later years. In other words, the S-shaped curve shifts to the left when $p$ is high and to the right when $\mathrm{q}$ is higher.

Considering $M$, the maximum number of adopters or potential market size at any given time $t$, the first time adoption $a(t)$ and the cumulative adoption $A(t)$ are obtained using the equations $a(t)=M \times f(t)$ and $A(t)=M \times F(t)$, where:

$$
f(t)= \begin{cases}F(t), & t=1 \\ F(t)-F(t-1), & t>1\end{cases}
$$

$F(t)$ is the proportion of the population $(M)$ that has adopted the innovation by the time $t$ and $f(t)$ is the proportion of $M$ that adopts the innovation at the time $t$.

The Bass model has been used in many instances to predict future adoption of new products or disease propagation. For example, Horvat, Fogliano, and Luning (2020) modified the bass diffusion model to study the adoption of insect-based food in Netherlands. Likewize, Maureal et al. (2020) used an adapted Bass diffusion model in their study to determine the time by which the COVID-19 propagation would flatten in the Philippines, as well as the risks of a second infection wave. In an earlier study, Kumar et al. (2007) used the Bass model to predict the adoption of mobile communication in Brazil, Russia, India and China (BRIC) and found that in the case of India, the coefficient of internal influence $q$, a measure of word-of-mouth was very high compared to other BRIC countries. They predicted a penetration of about 200 million cellular subscribers by 2015 . While their study suggested a plateau at that number, that would be true if everything else stayed the same. One goal for doing such predictions is to identify factors allowing the operators to beat the odds an extend their growth in the case of businesses, or to reduce the growth in the case of diseases.

\subsection{Logistic Diffusion Model}

The logistic function is an S-shaped or sigmoid curve initially used to model population growth and decline over time. Since the diffusion of technology-based products are similar to biological growth in terms of slow start and slow end, the logistic diffusion model is also widely used in forecasting the penetration of technology products as explained by Trappey and $\mathrm{Wu}(2008)$.

Berger (1981), Lee, Marcus and Lee (2011), Konstantinos and Vasilios (2011), and Trappey and Wu (2008) confirm that the logistic diffusion function is represented by the following mathematical equation:

$$
Y(t)=\frac{m}{1+a e^{-b t}}
$$

In this equation, $m$ is the ceiling or maximum value achieved by $Y(t)$; it is the maximum number of potential adopters 
or the highest total penetration achievable. The parameters $a$ and $b$ need to be estimated and respectively represent the initial penetration and the speed or rate of the diffusion.

\section{Data Description}

This study utilized seventeen months of information related to the penetration of gigabit Internet over FTTH in an overlay or brownfield deployment in the southwestern region of the United States. The collected data covered a period of 17 consecutive months from 2015 to 2016, thus considering the month as the unit of time $t$. This is consistent with prior diffusion studies. For example, in their study of mobile telephony diffusion, Michalakelis et al. (2008) considered the year as unit of time and used data from 12 annual mobile subscriptions. In a different study of fixed and mobile broadband diffusion, Lee, Marcus, and Lee (2011) used fixed broadband data over nine years (from 2000 to 2008) and mobile broadband data over six years (from 2003 to 2008) with the year as unit of time in both cases.

\section{Diffusion Analysis Methodology}

The data analysis was conducted using a phased approach. First, the data were split into two sets with the first twelve months used as training data and the remaining five months used to determine the accuracy of the model in forecasting future data. Michalakelis et al. (2008) used a similar approach in their study related to the diffusion model of mobile telephony in Greece on 12 data points.

Altogether, three models were created using a Microsoft Excel spreadsheet: one for Gompertz, one for Bass, and the third for the logistic function. The models were created by converting each equation to its corresponding formula. For example, the logistic diffusion function was coded as $=m /\left(1+a^{*} E X P\left(-b^{*} t\right)\right)$ with $m, a, b$, and $t$ pointing to specific cells on the spreadsheet. A representation of this model is on Figure 3, where $\$ C \$ 4$ stands for $m$; $\$ C \$ 2$ for $a$, $\$ \mathrm{C} \$ 3$ for $b$, and $\mathrm{B} 9$ for $t$.

\begin{tabular}{c|c|c|}
\hline$f_{x}=\$ C \$ 4 /(1+(\$ C \$ 2 * E X P(-(\$ C \$ 3 * B 9)))$ \\
\hline \hline D & E & F \\
\hline$Y(t)=\frac{m}{1+a e^{-b t}}$ & Residuals & \\
\hline Logistic & Squared Error & Increase by \\
\hline $1.01 \%$ & $1.5051 \mathrm{E}-05$ & \\
\hline $1.30 \%$ & $1.2275 \mathrm{E}-05$ & $0.29 \%$ \\
\hline
\end{tabular}

Figure 3. Partial representation of the logistic model created

In a report published by Sanford C. Bernstein, Kirjner et al. (2015) estimate that Google Fiber achieved a penetration of $20 \%$ in its first year in both Kansas City, KS and Kansas City, MO. This penetration went up to 25\% during its second year and was projected to exceed $40 \%$ by the end of the third year. Similarly, a report from the FTTH Council Europe (2016) confirmed that the FTTH take rate in Europe was at 28\% at the end of 2015. It is worth noting that the aforementionned reports considered all FTTH products and not just the gigabit Internet. In this study, the maximum number of possible adopters $m$ was set to $28 \%$ based on common practices in the marketing field and in alignment with various analysis. This is believed to be the maximum penetration achievable by the product, even though the penetration of other fiber products can be above this rate.

In creating the models, the goal consisted of identifying the best fit parameters such as $a$ and $b$ in the case of the Logistic model as presented in Figure 3. The best fit parameters are the ones that generate a function predicting values closely matching observed data. Because there are many possible values for a parameter, the data analysis used the ordinary least squares method (OLS) to select the best fit model. As such, the best model selected for each function was the one that minimized the sum of squared errors (SSE); an error being the difference between the model's estimated value and the corresponding observed value. In that regard, each of the three diffusion models was represented by its best fit model obtained using Microsoft Excel's add-ins tool known as the Solver. This tool finds the optimal value for a cell containing a formula by automatically adjusting values in a given range of cells as explained by Microsoft (2016). 
For all three models, the Generalized Reduced Gradient (GRG) option of the Solver was selected as compared to the LP Simplex and the Evolutionary options. Indeed, the GRG parameter is recommended for problems suggesting smooth and nonlinear data, while the LP Simplex is for linear problems, and the Evolutionary option is for non-smooth problems.

\section{Results, Model Evaluation and Comparison}

Based on data collected on the penetration of gigabit Internet over FTTH in a brownfield deployment, three best fit diffusion models were created using Gompertz, Bass, and logistic diffusion equations. In creating these models, the main goal consisted of identifying the optimal parameters that minimized the sum of squared errors between observed and predicted data. As such, the values of the parameters obtained for each model are presented on Table 1, along with their respective descriptions. Based on the values of these parameters, the three models forecasted the existing 12-month information along with the additional five months not used in the creation of the models.

Table 1. Diffusion models: parameters and optimal values based on the OLS method

\begin{tabular}{|c|c|c|c|c|}
\hline Model & SSE & Parameter & Value & Description \\
\hline & & $\mathrm{a}$ & 11.54488365 & $\begin{array}{l}\text { Inflexion point: point in time at which the growth } \\
\text { of adoption reaches its peak and starts decreasing }\end{array}$ \\
\hline \multirow[t]{3}{*}{ Gompertz } & $1.54847 \mathrm{E}-05$ & $\mathrm{~b}$ & 0.130589417 & Growth rate or pace of adoption of the innovation \\
\hline & & $\mathrm{m}$ & $28.00 \%$ & $\begin{array}{l}\text { Market potential or maximum number of possible } \\
\text { adaptors }\end{array}$ \\
\hline & & $\mathrm{p}$ & 0.012451104 & $\begin{array}{l}\text { Probability that a consumer will adopt the } \\
\text { innovation (coefficient of innovation) }\end{array}$ \\
\hline \multirow[t]{3}{*}{ Bass } & $2.53818 \mathrm{E}-05$ & $\mathrm{q}$ & 0.192732541 & $\begin{array}{l}\text { Probability of adoption by an imitator (coefficient } \\
\text { of imitation) }\end{array}$ \\
\hline & & $\mathrm{m}$ & $28.00 \%$ & $\begin{array}{l}\text { Maximum number of adopters or potential market } \\
\text { size }\end{array}$ \\
\hline & & $\mathrm{a}$ & 34.87314655 & Initial penetration \\
\hline \multirow[t]{2}{*}{ Logistic } & 10.2034E-05 & $\mathrm{b}$ & 0.264334811 & Speed or rate of the diffusion \\
\hline & & $\mathrm{m}$ & $28.00 \%$ & Ceiling or maximum number of potential adopters \\
\hline
\end{tabular}

A visual representation of the Gompertz model is shown on Figure 4; the Bass model is represented in Figure 5, and the Logistic model is shown in Figure 6.

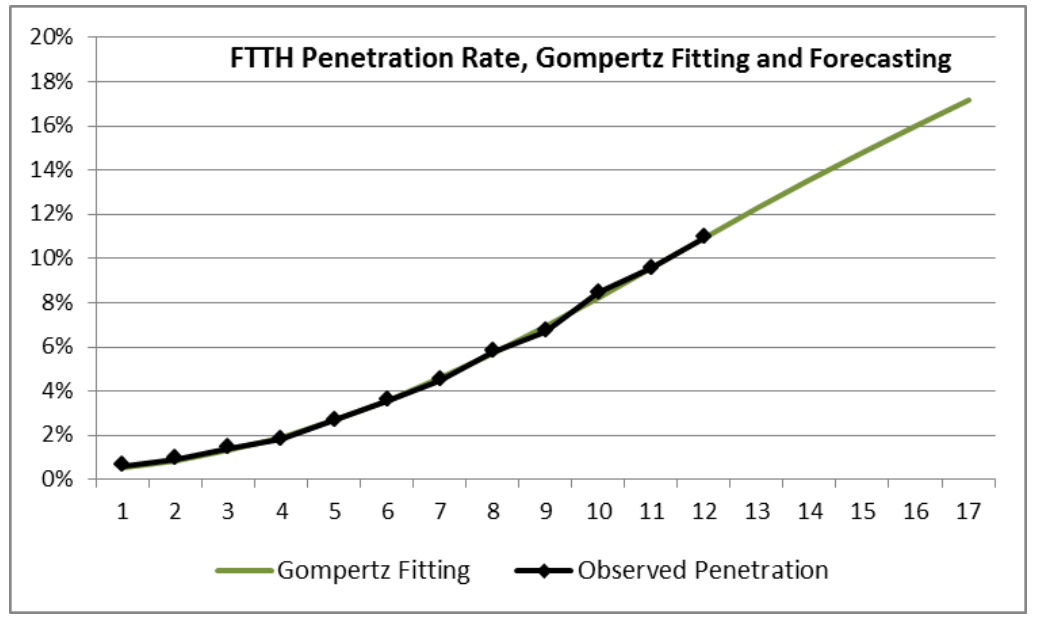

Figure 4. Gompertz model: Fitting observed data and forecasting retained values 


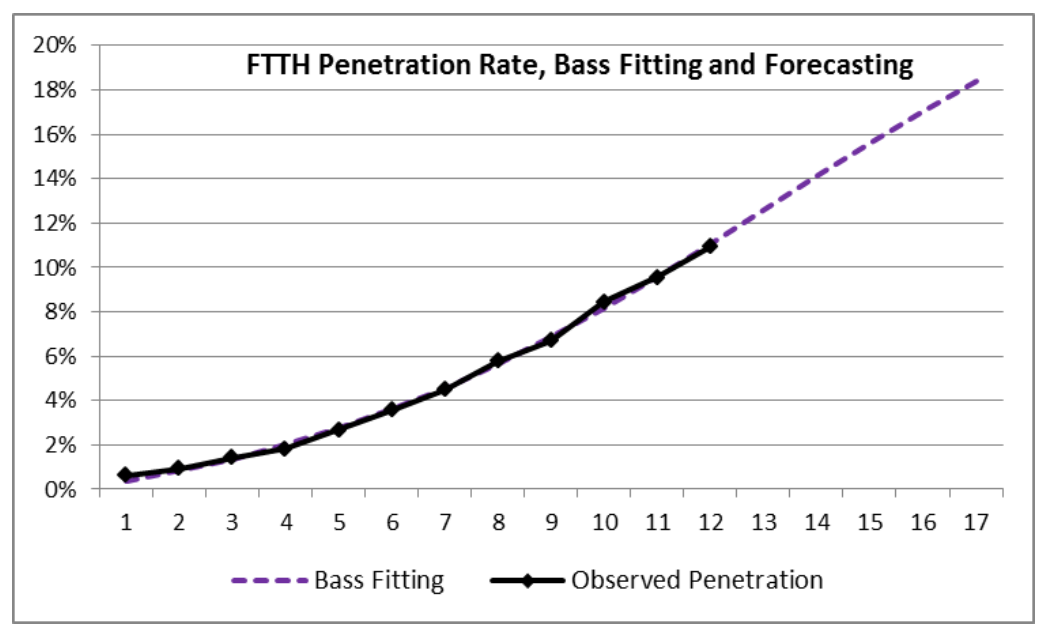

Figure 5. Bass model: Fitting observed data and forecasting retained values

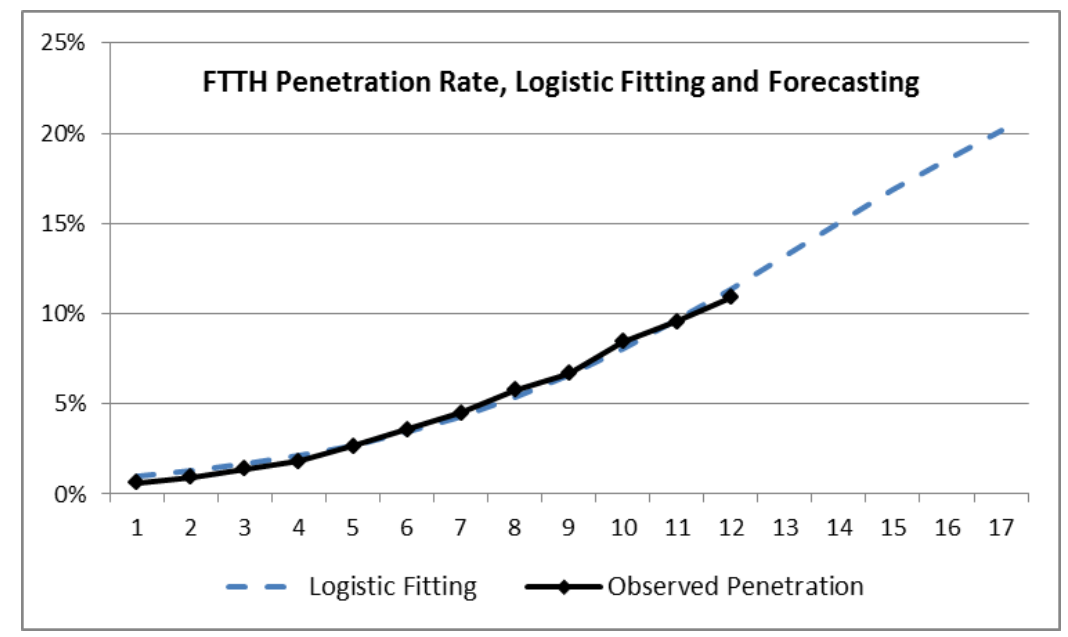

Figure 6. Logistic model: Fitting observed data and forecasting retained values

The parameters of the models as shown on Table 1 were obtained through adjustments to match the first 12 months of data as best as possible. The generated data and residuals of these models are presented on Table 2 for each observed value. The residuals represent the squared differences between the observed penetration rates and the values forecasted by the respective models. 
Table 2. Representation of the three models along with their squared errors

\begin{tabular}{llllllll}
\hline $\begin{array}{l}\text { Period } \\
(t)\end{array}$ & $\begin{array}{l}\text { Observed } \\
\text { Penetration }\end{array}$ & $\begin{array}{l}\text { Gompertz } \\
\text { Fitting }\end{array}$ & $\begin{array}{l}\text { Gompertz } \\
\text { Residuals }\end{array}$ & $\begin{array}{l}\text { Bass } \\
\text { Fitting }\end{array}$ & Bass Residuals & $\begin{array}{l}\text { Logistic } \\
\text { Fitting }\end{array}$ & $\begin{array}{l}\text { Logistic } \\
\text { Residuals }\end{array}$ \\
\hline 1 & $0.62 \%$ & $0.53 \%$ & $7.772 \mathrm{E}-07$ & $0.38 \%$ & $5.68953 \mathrm{E}-06$ & $1.01 \%$ & $1.51 \mathrm{E}-05$ \\
2 & $0.95 \%$ & $0.86 \%$ & $7.123 \mathrm{E}-07$ & $0.84 \%$ & $1.26311 \mathrm{E}-06$ & $1.30 \%$ & $1.23 \mathrm{E}-05$ \\
3 & $1.41 \%$ & $1.32 \%$ & $8.405 \mathrm{E}-07$ & $1.37 \%$ & $1.62687 \mathrm{E}-07$ & $1.67 \%$ & $6.45 \mathrm{E}-06$ \\
4 & $1.83 \%$ & $1.92 \%$ & $8.81 \mathrm{E}-07$ & $2.01 \%$ & $3.16806 \mathrm{E}-06$ & $2.14 \%$ & $9.39 \mathrm{E}-06$ \\
5 & $2.68 \%$ & $2.67 \%$ & $4.621 \mathrm{E}-09$ & $2.74 \%$ & $4.5632 \mathrm{E}-07$ & $2.72 \%$ & $1.85 \mathrm{E}-07$ \\
6 & $3.57 \%$ & $3.56 \%$ & $7.649 \mathrm{E}-09$ & $3.59 \%$ & $6.05743 \mathrm{E}-08$ & $3.44 \%$ & $1.62 \mathrm{E}-06$ \\
7 & $4.49 \%$ & $4.58 \%$ & $8.707 \mathrm{E}-07$ & $4.56 \%$ & $5.1266 \mathrm{E}-07$ & $4.32 \%$ & $2.8 \mathrm{E}-06$ \\
8 & $5.77 \%$ & $5.72 \%$ & $2.972 \mathrm{E}-07$ & $5.65 \%$ & $1.56664 \mathrm{E}-06$ & $5.38 \%$ & $1.57 \mathrm{E}-05$ \\
9 & $6.70 \%$ & $6.94 \%$ & $6.148 \mathrm{E}-06$ & $6.85 \%$ & $2.38758 \mathrm{E}-06$ & $6.62 \%$ & $6.17 \mathrm{E}-07$ \\
10 & $8.46 \%$ & $8.24 \%$ & $4.919 \mathrm{E}-06$ & $8.16 \%$ & $8.7162 \mathrm{E}-06$ & $8.05 \%$ & $1.71 \mathrm{E}-05$ \\
11 & $9.56 \%$ & $9.57 \%$ & $1.236 \mathrm{E}-08$ & $9.57 \%$ & $1.21683 \mathrm{E}-08$ & $9.64 \%$ & $7.09 \mathrm{E}-07$ \\
12 & $10.92 \%$ & $10.91 \%$ & $1.454 \mathrm{E}-08$ & $11.04 \%$ & $1.38624 \mathrm{E}-06$ & $11.37 \%$ & $2.02 \mathrm{E}-05$ \\
Sum of Squared Errors (SSE) & $1.548 \mathrm{E}-05$ & & $2.53818 \mathrm{E}-05$ & & 0.000102 \\
\hline 13 & $12.36 \%$ & $12.25 \%$ & $1.351 \mathrm{E}-06$ & $12.56 \%$ & $3.81837 \mathrm{E}-06$ & $13.19 \%$ & $6.89 \mathrm{E}-05$ \\
14 & $13.92 \%$ & $13.55 \%$ & $1.367 \mathrm{E}-05$ & $14.09 \%$ & $2.7064 \mathrm{E}-06$ & $15.04 \%$ & 0.000125 \\
15 & $15.26 \%$ & $14.81 \%$ & $2.043 \mathrm{E}-05$ & $15.59 \%$ & $1.08918 \mathrm{E}-05$ & $16.85 \%$ & 0.000253 \\
16 & $16.80 \%$ & $16.01 \%$ & $6.228 \mathrm{E}-05$ & $17.05 \%$ & $6.14729 \mathrm{E}-06$ & $18.57 \%$ & 0.000313 \\
17 & $18.14 \%$ & $17.15 \%$ & $9.86 \mathrm{E}-05$ & $18.43 \%$ & $8.37459 \mathrm{E}-06$ & $20.15 \%$ & 0.000403 \\
\multicolumn{1}{l}{ Total Sum $\%$} & & & $5.73202 \mathrm{E}-05$ & & 0.001265 \\
\hline
\end{tabular}

After fitting existing data to the adoption models, the Gompertz model provided the best representation of observed data with a sum of squared errors of 1.54847E-05 as shown on Table 1. This was followed by the by Bass model $(\mathrm{SSE}=2.53818 \mathrm{E}-05)$, and finally Logistic diffusion model (SSE=10.2034E-05). Similarly, the R-Square of all models was calculated and is shown on Table 3. The computation of the R-Square used the RSQ function in Excel, which returns the square of the Pearson moment correlation coefficient between observed and forecasted data. As expected, for the first twelve months, the Gompertz model produced the highest correlation, followed by Bass model and Logistic diffusion model.

Table 3. R-Square of Each Model

\begin{tabular}{llll}
\hline Period & Gompertz & Bass & Logistic \\
\hline Months 1-12 & 0.9988877 & 0.9982126 & 0.993181 \\
Months 13-17 & 0.9993603 & 0.9994878 & 0.999211 \\
Months 1-17 & 0.99860857 & 0.9994802 & 0.994385 \\
\hline
\end{tabular}

\section{Forecasting Results}

Even though the Gompertz model fitted the data best, it did not have the same forecasting power. Indeed, the Bass model produced a better R-Square for the forecasted data (Months 13-17) as indicated in Table 3, followed by Gompertz and Logistic. The Bass model fits the data best with an overall R-Square of $99.95 \%$, followed by Gompertz with an R-Square of $99.86 \%$, and Logistic with an R-Square of $99.44 \%$. This fit is confirmed by information on Table 2 with the Bass model showing an overall SSE of 5.73E-05, while Gompertz and Logistic respectively show SSEs of $21.18 \mathrm{E}-5$ and $126.50 \mathrm{E}-5$. This indicates that the Bass model produced less residual in 
forecasting the retained information and is thus more accurate in forecasting the penetration rate of the gigabit Internet over FTTH deployments.

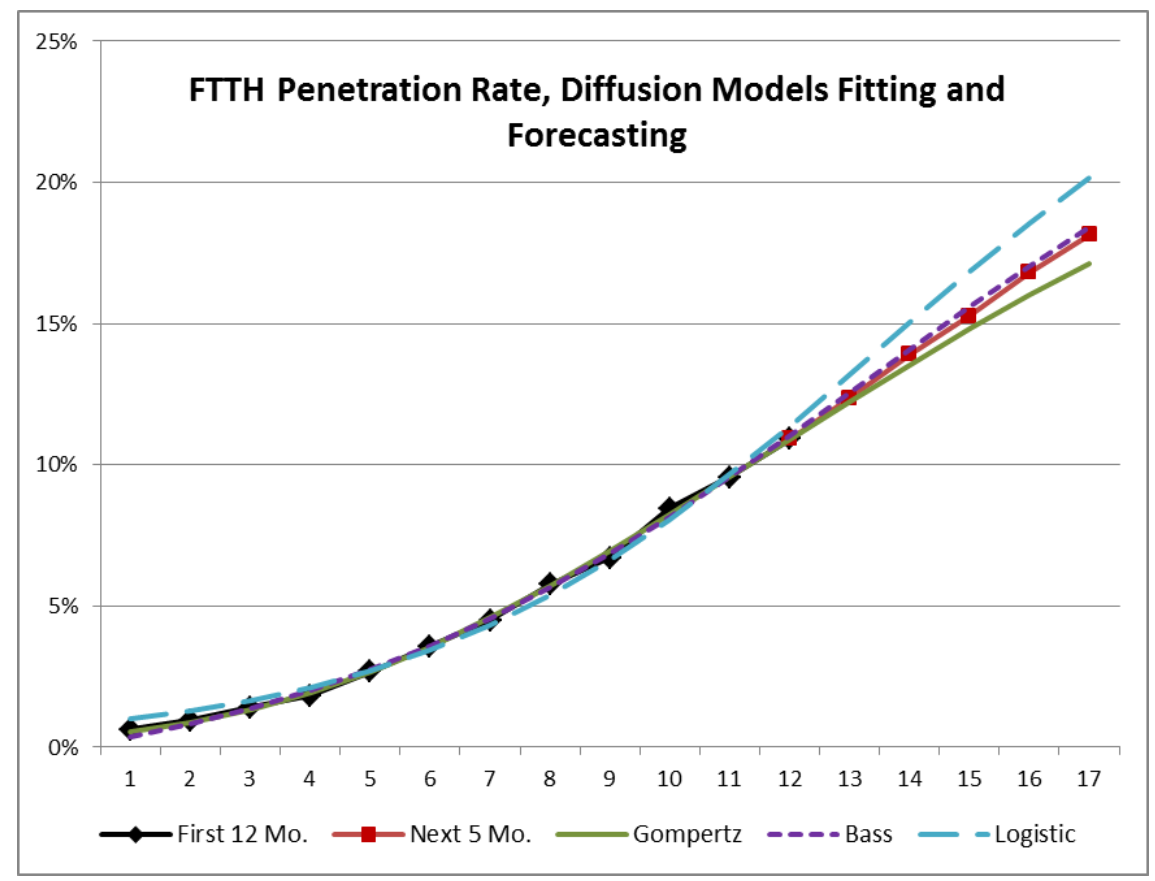

Figure 7. Diffusion Models fitting and forecasting: Observed and predicted data

A visual representation of the observed and the forecasted data is shown on Figure 7. The observed information is represented by two sets of data: one for the first 12 months and the other for the next 5 months. As shown in the Figure 7, the Logistic diffusion model has an optimistic estimation; the Gompertz model had a more pessimistic estimation; and the Bass model is more realistic and estimated the retained data with minimum deviation, thus its SSE of 5.73E-05 which is far better than that of the other models.

\section{Future Trends}

Using the same models presented and looking at future trends as shown on Figure 8, the Logistic model estimates the achievement of a $25 \%$ penetration rate at month 22 . The Bass model predicts it for month 24 and Gompertz estimates a $25 \%$ penetration during month 28 . As such, even though these models are so different, their estimates are just months apart. 


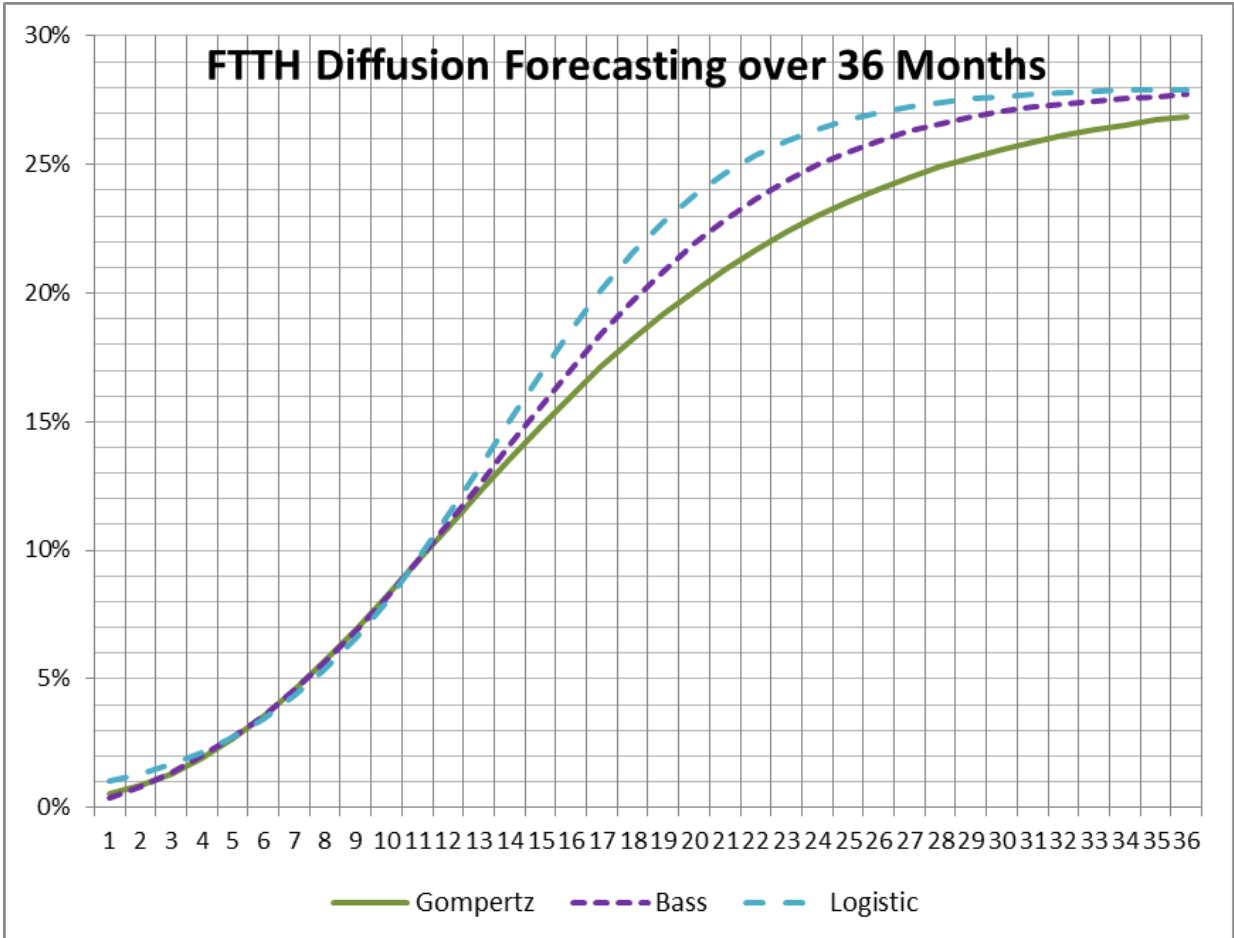

Figure 8. Model estimation of future trends

After 36 months, Bass and Logistic forecast the achievement of a penetration rate around $28 \%$. Gompertz on the other hand estimates the penetration rate to stay around $27 \%$. This is all based on a maximum achievable rate set at $28 \%$ at the creation of the model.

\section{Discussions}

In a previous study of the diffusion of mobile telephony using Bass, Gompertz, and Logistic diffusion models, Wu and Chu (2010) concluded that while the Gompertz model outperformed the others models prior to diffusion take-off, the Logistic model showed better results after the inflection point. That is aligned with the findings of the current study which showed that the Gompertz model had a better fit of existing data, while Bass and Logistic had better predictive powers leading to the expected maximum penetration. Gompertz on the other hand did not reach the maximum penetration after the first $36^{\text {th }}$ months.

In a different study of the diffusion of online shopping in Autstralia, Bakher Naseri and Elliott (2013) compared the same three diffusion models used in the current study namely Bass, Gompertz, and Logistic. After modelling online shopping data from 1998 to 2009, the authors indicated that the data could not be accurately represented using Gompertz and Logistic diffusion models. As such, they concluded that the Bass model outperformed both the Gompertz and Logistic models.

The findings from the current study confirm prior fingings from Bakher Naseri and Elliott, identifying the Bass model as best suited for forecasting the gigabit Internet product uptake in the broadband industry as it did for online sales. While Bakher Naseri and Elliott could not fit their data using Gompertz and Logistic, the current study diverges from theirs in the sense that Gompertz and Logistic were able to fit and project product uptake in the broadband industry.

\section{Conclusion}

The purpose of this paper was to identify a model that predicts future trends in the uptake of the FTTH gigabit Internet product. That was done through the implementation of three different diffusion models, namely Gompertz, Bass, and Logistic. The paper assumed that the reader had a basic understanding of the gigabit Internet over FTTH and presented a brief review of diffusion models. Data observed for 18 months were divided into two sets, one for the first twelve months and the other for the next five. The first dataset was used in creating the three models and the 
second was retained to validate the models' capability to forecast future penetration rates. The validation and fit of the models suggested that while the Gompertz model was good at fitting the first twelve months of observed data, the Bass model was better at predicting future values in the retained data, and best at fitting the overall dataset. Ultimately, the Gompertz model was pessimistic in its estimation of future penetration rates; the Logistic model was optimistic in its estimation; and the Bass model was realistic in forecasting future penetration rates.

\subsection{Limitations}

While achieving tangible results, this study presented some limitations. One such limitation is the number of data points available. The study had 17 months of data and built a model based on the first 12 months. Even though this was usable for the model creation, it would be good to obtain additional data points to build more robust models. Another limitation of the study is the consideration of a maximum penetration rage of 28 percent. While this information is the standard used in the broadband industry and in the company of interest, it is quite possible to achieve a higher penetration in some areas and this study did not take that into consideration.

\subsection{Implications}

The study presented here could be of great importance to marketing, sales, and financial departments of Internet service providers in general, and most specifically to companies providing or planning to provide the gigabit Internet service over fiber to the home. Indeed, the methodology and conclusions of the study can help these companies in establishing sales goals and anticipating financial results. As such, the return on investment could be estimated in advance and confirmed during the evolution of the project. Furthermore, strategic business decisions could derive from the information produced using these models and the methodology presented. For example, "what if" scenarios could be created to determine possible paths and answer questions such as: "At the current growth rate, is a penetration of $30 \%$ achievable?" or "How long would it take to achieve a penetration rate of $35 \%$ ?" These questions can be answered by making the maximum achievable rate become a variable rather than a constant and this can also constitute a subject for future research in the discipline.

\section{References}

Bakher Naseri, M., \& Elliott, G. (2013). The diffusion of online shopping in Australia: Comparing the Bass, Logistic and Gompertz growth models. Journal of Marketing Analytics, 1, 49-60. https://doi.org/10.1057/jma.2013.2

Bass, F. M. (1969). A new product growth for model consumer durables. Management Science, 15(5), 215-227. https://doi.org/10.1287/mnsc.15.5.215

Berger, R. D. (1981). Comparison of the Gompertz and Logistic Equations to describe plant disease progress. The Florida Agricultural Experiment Station, 71(7), 716-719. https://doi.org/10.1094/Phyto-71-716

Briglauer, W., \& Gugler, K. (2019). Go for Gigabit? First evidence on economic benefits of high-speed broadband technologies in Europe. Journal of Common Market Studies, 57(5), 1071-1090. https://doi.org/10.1111/jcms.12872

Campbell, B. G. (2015). Diffusion of innovations of videoconference technology: An instrumental case study concerning undergraduate degree-seeking nontraditional learners. Nova Southeastern University. Fischler College of Education: Theses and Dissertations.

Diaz Perez, F. J., Chinarro, D., Otin, R. P., Martín, R. D., Diaz, M., \& Mouhaffel, A. G. (2020). Comparison of Growth Patterns of COVID-19 Cases through the ARIMA and Gompertz Models. Case Studies: Austria, Switzerland, and Israel. Rambam Maimonides medical journal, 11(3). https://doi.org/10.5041/RMMJ.10413

FTTH Council Europe. (2016). FTTH Conference 2016: Calling for a brighter future. Luxembourg City, Luxembourg: Fibre to the Home Council Europe.

Horvat, A., Fogliano, V., \& Luning, P. A. (2020). Modifying the Bass diffusion model to study adoption of radical new foods - The case of edible insects in the Netherlands. PLOS ONE Collection. https://doi.org/10.1371/journal.pone.0234538

Kumar, A., Baisya, R. K., Shankar, R., \& Momaya, K. (2007). Diffusion of mobile communications: Application of Bass diffusion model to BRIC countries. Journal of Scientific \& Industrial Research, 66, 312-316.

Kirjner, C., de Sa, P., Rosso, A., Betcher, B., Chun, I., \& Zheng, J. (2015). U.S. Internet \& U.S. Telecom: What is behind Google Fiber's continued expansion? Does it matter for incumbents? New York: Sanford C. Bernstein \& Co.

Konstantinos, S., \& Vasilios, S. (2011). A new empirical Model for short-term forecasting of the broadband 
penetration- A short research in Greece. Hindawi Publishing Corporation, 1-10. https://doi.org/10.1155/2011/798960

Lartey, F. M. (2015). Increasing promoters in the residential broadband service industry: Relationship between customer satisfaction and loyalty using ordinal logistic regression. ProQuest LLC. UMI: 3682580

Levitt, M., Scaiewicz, A., \& Zonta, F. (2020). Predicting the Trajectory of Any COVID19 Epidemic From the Best Straight Line. medRxiv. https://doi.org/10.1101/2020.06.26.20140814

Lee, S., Marcu, M., \& Lee, S. (2011). An empirical analysis of fixed and mobile broadband diffusion. Information Economics and Policy, 23(3-4), 227-233. https://doi.org/10.1016/j.infoecopol.2011.05.001

Maureal, Z. L., Lapates, J. M., Dumandan, M. S., Bicar, V. K. B., \& Gaylo, D. N. (2020). Adapted Bass diffusion model for the spread of COVID-19 in the Philippines: Implication to interventions and flattening the curve. International Journal of Innovation, Creativity and Change, 14(3), 1418-1437.

Meade, N., \& Islam, T. (1995) Forecasting with growth curves: An empirical comparison. International Journal of Forecasting, 11(2), 199-215. https://doi.org/10.1016/0169-2070(94)00556-R

Meade, N., \& Islam, T. (2006) Modelling and forecasting the diffusion of innovation - A 25-year review. International Journal of Forecasting, 22(3), 519-545. https://doi.org/10.1016/j.ijforecast.2006.01.005

Michalakelis, C., Varoutas, D., \& Sphicopoulos, T. (2008). Diffusion models of mobile telephony in Greece. Telecommunication Policy, 234-245. https://doi.org/10.1016/j.telpol.2008.01.004

Microsoft. (2019). Define and solve a problem by using Solver. Retrieved from Support.Office.Com: https://support.microsoft.com/en-us/office/define-and-solve-a-problem-by-using-solver-5d1a388f-079d-43ac-a7 eb-f63e45925040

Radojicic, V., Markovic, G., Jankovic, M., \& Draskovic, B. (2012). Broadband traffic forecasting in the transport network. Information and Communication Technology, 24(4), 275-284. https://doi.org/10.7307/ptt.v24i4.440

Robinson, L. (2009). A summary of diffusion of innovations. Enabling Change. Retrieved from http://www.enablingchange.com.au/Summary_Diffusion_Theory.pdf

Rogers, E. M. (1976). New product adoption and diffusion. Journal of Consumer Research, 2, 336-347. https://doi.org/10.1086/208642

Rogers, E. M. (1983). Diffusion of innovations (3rd ed.). New York: The Free Press, A Division of Macmillan Publishing Co.

Rogers, E. M. (2003). Diffusion of innovations (5th ed.). New York: Free Press.

Skiadas, C. H., \& Skiadas, C. (2010). Comparing the Gompertz-type models with a first passage time density model. Advances in Data Analysis, 203-209. https://doi.org/10.1007/978-0-8176-4799-5_18

Stragier, J., Seys, C., Evens, T., Evenepoel, S., Ooteghem, J. V., \& Casier, K. (2012). A priori forecasting of FTTH uptake: Connecting segmentation forecasting to timing forecasting. Research Gate, Universiteit Gent, 1-7. Retrieved from https://biblio.ugent.be/publication/2958274/file/2958298.pdf

Sudtasan, T., \& Mitomo, H. (2017). Comparison of diffusion models for forecasting the growth of broadband markets in Thailand. 14th Asia-Pacific Regional Conference of the International Telecommunications Society (ITS): "Mapping ICT into Transformation for the Next Information Society", Kyoto, Japan, June 24-27, International Telecommunications Society (ITS).

Trappey, C. V., \& Wu, H.-Y. (2008). An evaluation of the time-varying extended logistic, simle logistic, and Gompertz models for forecasting short product lifecycles. Advanced Engineering Informatics, 421-430. https://doi.org/10.1016/j.aei.2008.05.007

Turk, T., \& Trkman, P. (2012). Bass model estimates for broadband diffusion in European countries. Technological Forecasting \& Social Change, 79(1), 85-96. https://doi.org/10.1016/j.techfore.2011.06.010

Wu, F., \& Chu W. (2010). Diffusion models of mobile telephony. Journal of Business Research, 63(5), 497-501. https://doi.org/10.1016/j.jbusres.2009.04.008

Young, P. (1993) Technological growth curves: A competition of forecasting models. Technological Forecasting and Social Change, 44(4), 375-389. https://doi.org/10.1016/0040-1625(93)90042-6 


\section{Copyrights}

Copyright for this article is retained by the author(s), with first publication rights granted to the journal.

This is an open-access article distributed under the terms and conditions of the Creative Commons Attribution license (http://creativecommons.org/licenses/by/4.0/). 